\title{
Allez Hop, a nationwide programme for the promotion of physical activity in Switzerland: what is the evidence for a population impact after one decade of implementation?
}

\author{
Miriam Wanner, ${ }^{1,2}$ Eva Martin-Diener,1,2 Georg F Bauer, ${ }^{2,3}$ Hanspeter Stamm, ${ }^{4}$ \\ Brian W Martin ${ }^{1,2}$
}

${ }^{1}$ Swiss Federal Institute of Sport Magglingen, Magglingen, Switzerland Institute of Social and Preventive Medicine, University of Zurich, Zurich, Switzerland

${ }^{3}$ Centre for Occupational and Organisational Sciences, ETH Zurich, Zurich, Switzerland ${ }^{4}$ Observatory Sport and Physical Activity, Lamprecht 8 Stamm (L\&S) Sozialforschung und Beratung AG, Zurich, Switzerland

\section{Correspondence to} Dr Miriam Wanner, Institute of Social and Preventive Medicine, University of Zurich, Pestalozzistrasse 24, $\mathrm{CH}-8032$ Zurich, Switzerland; miriam.wanner@ physicalactivityandhealth.ch

Accepted 13 April 2010 Published Online First 11 June 2010

\begin{abstract}
Objectives To present evidence for a population impact of a national physical activity promotion programme after a decade of implementation.

Methods The programme Allez Hop offered local physical activity courses (mainly walking and Nordic walking) once a week over 12 weeks. Data from a pretest posttest survey in 2005 course participants $(\mathrm{N}=2157$ at baseline (of 4130, 52.2\%), 1587 at first follow-up (73.6\%); smaller subsample with second follow-up) and from repeated cross-sectional national surveys have been analysed regarding changes in physical activity behaviour.
\end{abstract}

Results The total number of Allez Hop courses was 18684 between 1997 and 2008. 89.2\% of participants were women, the mean age was 48.5 years. The proportion meeting the physical activity recommendations was $31.7 \%$ at baseline, in participants with first follow-up data it increased from $33.1 \%$ to $42.3 \%$ $(p<0.001)$. On the population level in the main user group of Allez Hop (middle-aged women) the proportion not engaging in any sport decreased from $50.1 \%$ (1997) to $47.2 \%$ (2002) and to $43.1 \%$ (2007) $(p<0.01)$. Walking/hiking was the second most frequently performed sport (33.7\%) in 2007, with the most remarkable increase since $2000(+11.1 \%)$.

Conclusions Allez Hop was successfully implemented for more than a decade, reached middle-aged women and a high proportion of insufficiently active individuals. Changes in participants' physical activity behaviour must be interpreted cautiously because of low response rates and short follow-up. However, indications for behavioural changes were observed at the population level, even though these data do not allow a causal link to Allez Hop.

Physical activity has been recognised as an important public health issue, ${ }^{1}$ and many countries are currently in the process of developing and implementing respective policies and strategies. ${ }^{2}$ Attempts at promoting sports for all have an even longer history. Given the solid evidence on the health effects of walking, ${ }^{3}$ many countries are now promoting such activities in particular, for example, the "Walking the Way to Health' programme in England ${ }^{4}$ and the 'Paths to Health' programme in Scotland. ${ }^{5}$ While there is some evidence about the effectiveness of interventions for the promotion of walking, ${ }^{6}$ there is only very limited documented evidence for the effectiveness of sports programmes in promoting physical activity at the population level and only a few national multi-year physical activity promotion programmes have been systematically analysed. ${ }^{7-10}$

Switzerland (population of 7.1 million in 1996) has a strong tradition of sports clubs, with approximately one quarter of the adult population being members; ${ }^{11}$ it has successfully implemented the national programme 'Youth and Sport' for adolescents since the 1970s, and it has an excellent walking infrastructure including a network of approximately $60000 \mathrm{~km}$ hiking trails. Nevertheless, the first national representative data on physical activity behaviour in Switzerland showed that the proportion of individuals reporting less than one vigorous exercise episode per week increased from $35.7 \%$ in 1992 to $39.4 \%$ in 1997.12

Allez Hop as a nationwide programme for the promotion of physical activity was launched in 1997 as a joint initiative of three Swiss health insurance companies and the Swiss Olympic Association, the umbrella organisation of Swiss sports federations. Later, the single health insurance companies were replaced by Santésuisse, their national umbrella organisation, and the foundation Health Promotion Switzerland as well as the Swiss Federal Office of Sport joined the partners behind the project. In 2003 the overall responsibility for the programme changed from the Swiss Olympic Association to the Federal Office of Sport. The core of the programme were local physical activity courses offered by trained and qualified Allez Hop instructors once a week for approximately 12 weeks, targeted at inactive and insufficiently active adults. Course disciplines included gymnastics, walking, tennis, water gymnastics, Nordic walking, running and Fitgym (indoor conditioning exercises). The budget of Allez Hop was approximately €1.5 million per year between 1998 and 2001 and approximately $€ 0.8$ million thereafter. The budget was originally participation-driven, with increasing costs for each additional course. To absorb these costs despite a decreasing budget, a franchising system was introduced in 2004 requiring Allez Hop instructors to obtain a licence in order to offer courses under the label 'Allez Hop'. In addition, Allez Hop implemented self-financing strategies through merchandising and course offers 
for companies, generating $€ 0.3$ million annually by the year 2006. Allez Hop has always been an implementation and not a research project. There was no constant and consistent evaluation strategy, but several evaluation projects have been carried out. ${ }^{13-16}$ Based on findings that a number of participants took part in more than one course, so-called Allez Hop 'meetings' were created for experienced participants wishing to continue their physical activities in a structured format with qualified guidance.

The experiences of a national long-term physical activity programme with the promotion of leisure-time walking as one of its main aims may also be of interest to other countries. Therefore, this publication is looking at the following research questions: What was the success in developing the programme and what was its reach over more than a decade? What were the characteristics of its users and what were indications for behavioural change in them? What were the indications for changes in behavioural patterns at the population level?

\section{METHODS}

\section{Data assessments}

\section{Development and utilisation of the programme Allez Hop}

The central course registration system used for the financial reimbursement of instructors and the advertisement of courses provided the Allez Hop course database. Allez Hop instructors registered the courses they offered over the internet or by email. Data regarding the development of Allez Hop courses were derived from that database and could be stratified by course discipline and year.

\section{Course evaluations in 2005}

A written questionnaire survey was carried out among all course participants of Allez Hop walking and Nordic walking courses that started in April and ended in July 2005. Participants were asked to complete questionnaires with items on course expectations, course satisfaction, physical activity behaviour and sociodemographic variables at the beginning (baseline) and the end (first follow-up) of the course. In a subsample in three regions (Aargau representing the German-speaking, Romandie the French-speaking and Tessin the Italian-speaking parts of Switzerland), course participants were furthermore asked to complete a second follow-up assessment 3 months after the end of the courses in October. An originally planned third follow-up after 1 year was not carried out because of the low response already at the second follow-up (see Results section for response).

$\chi^{2}$ Tests for categorical variables and t tests for continuous variables were used to examine differences between regions at baseline. McNemar tests were applied to examine changes in physical activity behaviour over time.

\section{Swiss Health Survey 1997, 2002 and 2007}

The Swiss Health Survey is a representative repeated crosssectional survey assessing data on a number of health variables, including physical activity behaviour. The survey has been carried out every 5 years since 1992 in a random sample of Swiss adults above 15 years of age. Computer-assisted telephone interviews were used to assess the data presented here (1997, 2002 and 2007). The numbers of participants (response) for the respective years were: 13004 (69\%), 19706 $(64 \%)$ and $18760(66.3 \%)$. In order to be representative of the Swiss population, the data were weighted according to gender, age, linguistic region and nationality. To compare physical activity behaviour between survey years, SE were calculated using the complex sample command, and $z$ tests were used to derive $p$ values. The survey is described in more detail elsewhere. ${ }^{17}$

\section{Sports surveys in 1999 and 2007}

Two representative cross-sectional sports surveys were carried out in 1999 and in 2007. The main purpose of the surveys was the assessment of sports preferences and habits in the Swiss population. In 1999, a representative sample of the population aged 14-74 years was selected based on a random-random procedure and interviewed using computer-assisted telephone interviews ( $\mathrm{N}=2064$, response $56.8 \%$ ). In order to represent the Swiss population, the data were weighted according to age, household size and language region. Similarly, the survey in 2007 was carried out in several regionally representative samples aged 15-74 years using a random-random procedure. Data were assessed using computer-assisted telephone interviews ( $\mathrm{N}=10262$, response $55.0 \%$ ). To account for the different regional sample sizes and to represent the general Swiss population, the data were weighted according to gender, age and region. The surveys are described in more detail elsewhere. ${ }^{11} 18$

\section{Outcome measures}

The main outcome measure in the 2005 course evaluations was the proportion of participants meeting the health-enhancing physical activity (HEPA) recommendations ( $\geq 30 \mathrm{~min}$ of moderate intensity activities on $\geq 5$ days per week or $\geq 20$ min of vigorous intensity activities on $\geq 3$ days perweek). At the population level, the proportion of the Swiss population that did not engage in any sport, fitness activities or gymnastics was analysed for 1997, 2002 and 2007. The proportion of individuals engaging in specific sports activities was assessed in 2000 and 2007 (of respondents who reported participating in any sport).

\section{RESULTS}

\section{Participation in Allez Hop}

Figure 1 shows the development of Allez Hop courses according to the different course disciplines between 1997 and 2008 (data for 2008 not available by course discipline). An increasing number of courses were offered, with a peak of 2174 courses in 2003 and a levelling off thereafter. The total number of registered courses amounts to 18684 . Nordic walking evolved as the main course discipline after 2003. In more recent years, approximately one-third to one-quarter of the courses were Allez Hop 'meetings'.

\section{Course evaluations in 2005: response}

A total of 356 walking and Nordic walking courses started in April 2005. Approximately 6000 questionnaires were handed out to course instructors. The estimated number of course participants, based on a mean number of 11.6 individuals per course, ${ }^{15}$ was 4130 . Of those, 2157 completed the baseline questionnaire $(52.2 \%)$ at the beginning of the courses. Records from baseline and first follow-up (beginning and end of the courses) were available for 1587 participants $(73.6 \%$ of baseline respondents). There were no significant differences between respondents and non-respondents at the first followup regarding gender $(p=0.87)$, age $(p=0.52)$ and meeting the HEPA recommendations $(\mathrm{p}=0.81)$.

In the subsample selected for participation in the second follow-up, 483 (358 in German-speaking, 81 in French- 
speaking and 44 in Italian-speaking Switzerland) of the 580 questionnaires distributed at baseline were returned (83.3\%). First follow-up questionnaires were available for 313 participants (64.8\% of baseline respondents). Of 216 individuals who agreed to take part in the second follow-up assessment, 169 responded $(78.2 \%)$. This corresponds to a response of $29.1 \%$ of the 580 distributed questionnaires and of $35.0 \%$ of the 483 baseline respondents. Complete records regarding physical activity behaviour for all three assessments were available for 141 individuals. There were no significant differences between those who responded at the second follow-up and those who did not regarding gender $(p=0.34)$, age $(p=0.20)$ and meeting the HEPA recommendations at baseline $(p=0.11)$.
Course evaluations in 2005: characteristics of participants at baseline

At baseline, $89.2 \%$ of the course participants were women $(\mathrm{N}=2157)$. The mean age was 48.5 years, with a range of 13-87 years. Of the respondents, $2.4 \%$ were from the Italianspeaking, $17.9 \%$ from the French-speaking and $79.7 \%$ from the German-speaking parts of Switzerland. The proportion of women was highest in the Italian-speaking part, with $95.7 \%$; in the French and German-speaking parts the corresponding values were $92.7 \%$ and $88.5 \%$, respectively $(p=0.02)$. The mean age was highest in the French-speaking part, with 51.0 years compared with 50.2 years in the Italian and 47.8 years in the German-speaking parts $(p<0.01)$.

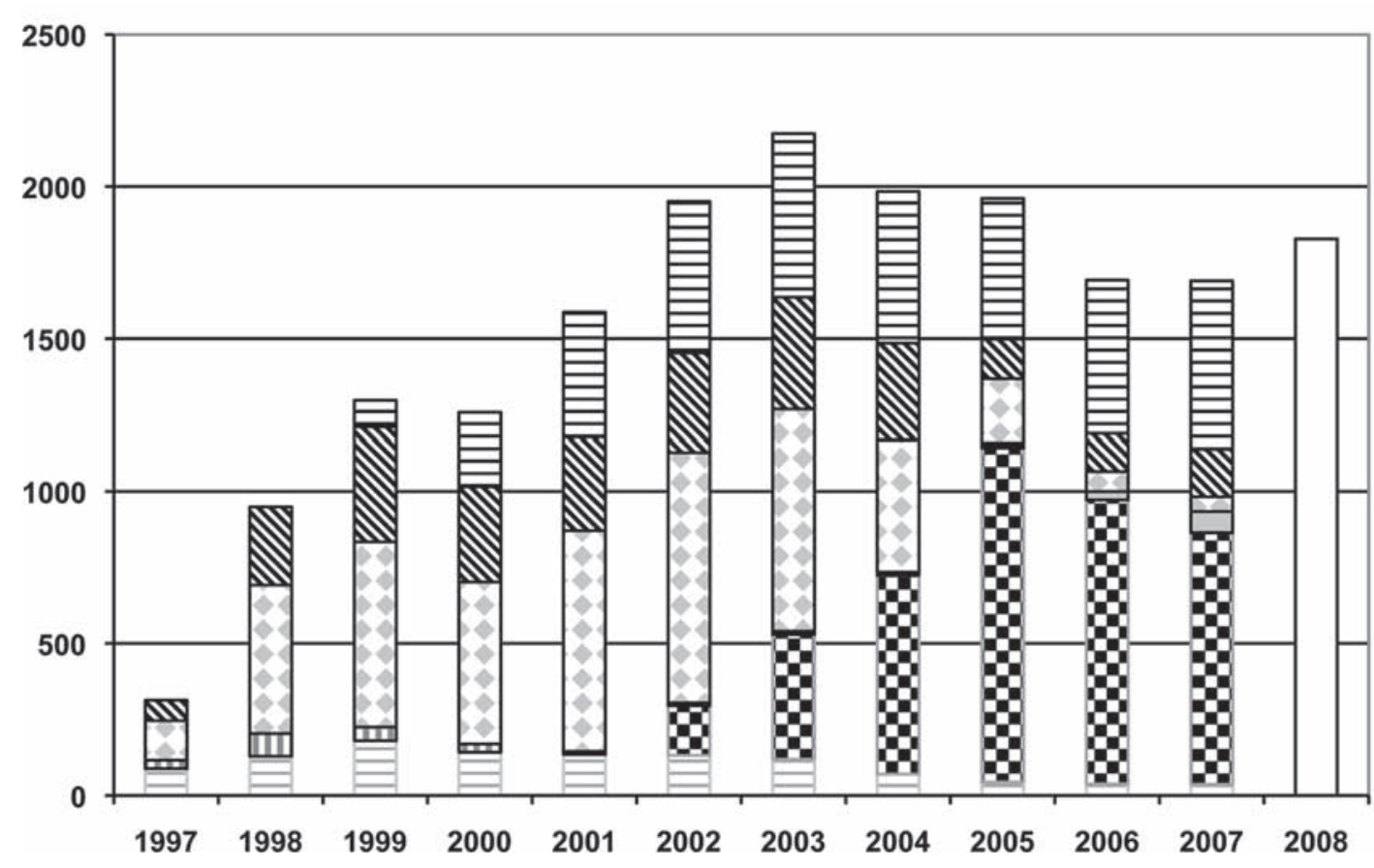

日"meetings"

هWater gymnastics

aWalking

口Tennis

-Dancing

Running

× Nordic walking

FitGym

口Total courses 2008

Figure 1 Development of Allez Hop courses and 'meetings' between 1997 and 2008, by course discipline. Data were not available by course discipline for 2008.
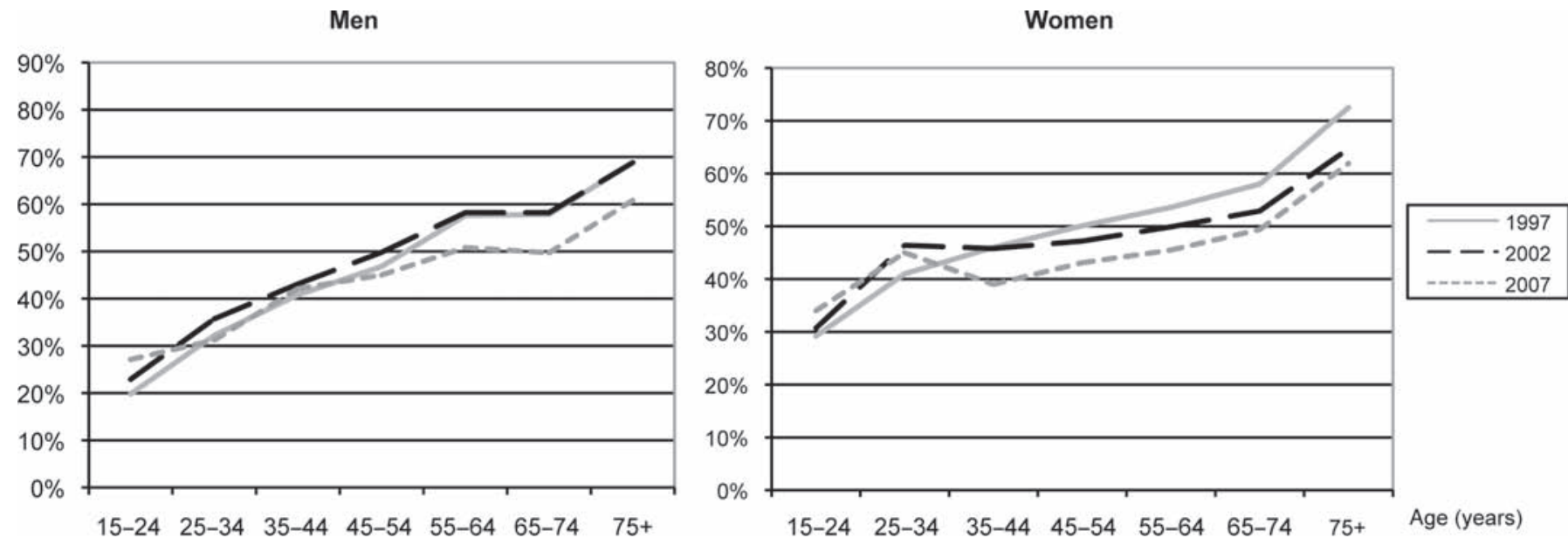

Figure 2 Changes in the proportion of men and women that did not engage in any sport, fitness activities or gymnastics (based on the Swiss Health Survey) between 1997 and 2007. 
A total of $31.7 \%$ of the participants with complete physical activity data $(\mathrm{N}=1822)$ met the HEPA recommendations at baseline. The proportion was highest in the Germanspeaking part, with $33.2 \%$ compared with the French $(27.2 \%)$ and the Italian-speaking parts $(16.7 \%, p=0.01)$, although the number of complete responses from the Italian part was very low.

\section{Course evaluations in 2005: changes in behaviour}

The proportion meeting the HEPA recommendations increased significantly from $33.1 \%$ at baseline to $42.3 \%$ at the first follow-up (individuals with complete data at both time points, $\mathrm{N}=1213, \mathrm{p}<0.001)$. The patterns were similar in all regions, with significant increases in the German $(p<0.001)$ and the French-speaking parts $(p=0.001)$, but a non-significant increase in the Italian-speaking part.

For the subgroup participating in all three surveys including the second follow-up ( $\mathrm{N}=141)$, the proportion meeting the HEPA recommendations increased significantly from $30.5 \%$ at baseline to $40.4 \%$ at the first follow-up ( $p=0.03$ ), but decreased to baseline levels at the second follow-up in autumn $(27.7 \%, p=0.006)$. There were no significant differences between baseline and second follow-up $(p=0.62)$. The patterns were similar in the German-speaking and the Italian-speaking parts. In the French-speaking part, physical activity levels increased from $29.2 \%$ (baseline) to $33.3 \%$ (first follow-up) and to $41.7 \%$ (second follow-up); however, these changes were not significant.

At the second follow-up, $36.0 \%$ of the respondents participated in either another Allez Hop course (11.0\%) or an Allez Hop 'meeting' (18.3\%) or both $(6.7 \%)$; $4.8 \%$ had joined a sports club after the end of the Allez Hop course.

\section{Changes in behaviour at the population level}

Figure 2 shows the changes in the proportion of men and women (by age group) that did not engage in any sport, fitness activities or gymnastics based on the Swiss Health Survey. In the main user group of Allez Hop (women aged 45-54 years), the proportion decreased from 50.1\% in 1997 to $47.2 \%$ in 2002 and to $43.1 \%$ in $2007(\mathrm{p}<0.01)$. The corresponding proportions for men of the same age group were $46.8 \%$ in $1997,49.8 \%$ in 2002 and $45.0 \%$ in 2007 (not significant).

Between 1999 and 2007, the proportion of individuals who participated in any sport increased from $71.8 \%$ to $72.9 \%$ in the Swiss sports surveys, the proportion doing sports at least once a week even from $62.9 \%$ to $66.7 \%$. Table 1 presents the proportion of men and women who engaged in specific sporting activities in 1999 and 2007 (of those who participated in any sport, $1999 \mathrm{~N}=1481 ; 2007 \mathrm{~N}=7481$ ). The presented activities refer to those sports named by $10 \%$ or more of individuals. After bicycling/mountain biking, walking/hiking was the second most popular sport (33.7\%) according to the 2007 sports survey. Walking/hiking was not only one of the most popular sports activities, it has also experienced the most remarkable increase, with $11.1 \%$ between 1999 and 2007.

\section{DISCUSSION}

Allez Hop, a nationwide programme to promote physical activity, has been successfully implemented in Switzerland for more than a decade. Over 18000 courses were realised, with a mean of 11.6 participants per course, ${ }^{19}$ resulting in approximately 200000 participants in total, although up to one-third of them may have been multiple participants. The main user group was middle-aged women, and Allez Hop has succeeded in reaching a high proportion of insufficiently active individuals $(68.3 \%$ in 2005 compared with $64.1 \%$ in the general Swiss population in 2002). ${ }^{12}$ Although the reduction in funding coupled with the change to a franchising system did not result in a large decrease regarding course numbers, the slight decrease after 2003 may be attributable to a delayed effect of these budgetary changes. Other reasons may be a high number of trained instructors not offering any courses, ${ }^{19}$ dwindling institutional support, and other private and commercial organisations starting to offer similar physical activity courses competing with Allez Hop.

Allez Hop has reached quite a high level of awareness in the Swiss population, which has moreover risen continuously. According to a demographic market research survey, only $8 \%$ of the population in Switzerland had heard about Allez Hop in March 1998 before the start of a large advertising campaign. ${ }^{1520}$ Two months after the end of the campaign in July 1998, 21\% had heard about Allez Hop. ${ }^{20}$ According to two population surveys, $20 \%$ and $22 \%$ of the population had heard about Allez Hop in 2001 and 2002, respectively. ${ }^{21}$ Finally in 2004, 26\% knew about Allez Hop. ${ }^{21}$ The national programme 'Youth and Sport' has reached a much higher level of awareness (86.2\% in 2004); ${ }^{21}$ however, 'Youth and Sport' has been implemented for more than 30 years based on the national law on the promotion of physical education and sport (1972), has a federal budget of approximately $€ 37$ million per year, and is well disseminated in the population with more than half a million adolescents participating in the programme every year. Despite the difference in levels of awareness, the acceptance and appreciation of the two programmes in the population was similarly high (data not shown). ${ }^{21}$

Table 1 Most popular sports activities in Switzerland in 1999 and 2007 for men and women aged 15-74 years (including those sports named by at least $10 \%$ of the population)

\begin{tabular}{|c|c|c|c|c|}
\hline & \multicolumn{2}{|c|}{ Men (aged 15-74 years) } & \multicolumn{2}{|c|}{ Women (aged 15-74 years) } \\
\hline & Level 1999 & Level 2007 & Level 1999 & Level 2007 \\
\hline Bicycle, mountain bike & $31.9 \%$ & $38.4 \%$ & $31.5 \%$ & $31.7 \%$ \\
\hline Walking/hiking* & $18.2 \%$ & $29.4 \%$ & $26.9 \%$ & $37.9 \%$ \\
\hline Swimming & $21.1 \%$ & $20.7 \%$ & $31.3 \%$ & $30.0 \%$ \\
\hline Skiing & $19.2 \%$ & $22.9 \%$ & $16.9 \%$ & $20.6 \%$ \\
\hline Jogging/running & $19.6 \%$ & $19.1 \%$ & $15.7 \%$ & $14.6 \%$ \\
\hline Fitness training & $8.2 \%$ & $11.2 \%$ & $14.8 \%$ & $16.8 \%$ \\
\hline General gymnastics & $7.3 \%$ & $7.7 \%$ & $26.4 \%$ & $15.6 \%$ \\
\hline
\end{tabular}

*Walking/hiking was composed of two-thirds hiking and one-third walking, the latter including $47 \%$ Nordic walking, $20 \%$ walking and $33 \%$ brisk walking in 2007. 
Previous $^{13}$ and current evaluation attempts have not succeeded in creating satisfying evidence for changes in physical activity behaviour in Allez Hop course participants. The data presented in this article showed an increase in physical activity behaviour between the beginning (April) and end of the courses (July), but activity levels were back to baseline levels at the second follow-up in October. It is unclear whether this indicates a lack of effectiveness of the intervention, or whether physical activity levels actually improved after taking into account seasonal variations in behaviour. This distinction was not possible due to the lack of a synchronous control group. Furthermore, the low response made it impossible to carry out a third follow-up 1 year after baseline in April when spontaneous physical activity levels would be expected to be higher than in autumn or winter. Therefore, the results do not allow meaningful interpretation. Different reasons are responsible for these limitations. First, Allez Hop started as an implementation rather than a research project, and measuring behavioural changes was not a priority. Second, there was a lack of an overarching evaluation concept and there were changing conditions regarding sponsorship, political priorities and organisational aspects. ${ }^{22}$ Planning of programme development and evaluation was thus difficult in the long term. There is no doubt that a randomised study design would be desirable to test the effectiveness of Allez Hop thoroughly compared with a control group in order to account for seasonal variations in physical activity behaviour; however, in communitywide studies this may be challenging, and quasi-experimental, or even good time series population surveillance might be all that could be achieved to improve future evaluations. It is generally acknowledged that randomised controlled trials are often not feasible or are even inappropriate to evaluate public health interventions. ${ }^{23} 24$ Further analyses of the 2005 course evaluations showed that acceptance and appreciation of the programme was high in participants overall (data not shown, but comparable to results published for course evaluations in 2006 and 2007/8). ${ }^{16}$

Data from population-based cross-sectional surveys show increases in physical activity levels in the main user group of Allez Hop (middle-aged women) between 1997 and 2007, and remarkable increases especially in walking (including Nordic walking), which became one of the most popular activities offered in Allez Hop courses. In fact, Allez Hop has probably contributed to the rise of Nordic walking in Switzerland. These data indicate a potential impact on the population level, even though they do not allow a causal link to specific programmes such as Allez Hop. The high level of awareness and appreciation of Allez Hop in the population ${ }^{21}$ support evidence for a positive impact at the population level.

Ideally, large population-based programmes such as Allez Hop are based on national physical activity promotion policies, which justify and support the programme politically. Since 2000, Switzerland has a 'federal government's concept for a national sport policy', ${ }^{25}$ in which Allez Hop is named as one measure to promote physical activity in adults. ${ }^{26}$ This commitment was renewed for the period 2007-10. ${ }^{26}$ Nevertheless, Allez Hop as a national implementation project was terminated at the end of 2008 and only the instructors' training was integrated into the new concept 'sports for adults' of the Swiss Federal Office of Sport. Two regional organisations are continuing with the label Allez Hop in the Italian and the Frenchspeaking parts of Switzerland.

Althoughitseems obvious thatlong-term planning and implementation of physical activity promotion projects-ideally coupled with repeated evaluation and adaptation-are desirable, this is far from the norm. Out of the four national programmes from European countries analysed in the 1990s, 8 only the Finnish 'Fit for Life' is still active 10 years later. Not only Allez Hop, but also 'The Netherlands on the Move' and the English 'Active for Life' have been discontinued, in the earlier case together with the transfer of the responsibility for physical activity promotion from the 'Netherlands Olympic Comittee/Netherlands Sports Confederation NOC/NSF' to the new National Institute for Sport and Physical Activity, in the latter case with the dismantling of the organising health education authority. ${ }^{27}$

It is possible that local, regional or entirely private structures can take over the legacy of Allez Hop. However, particularly the outreach to insufficiently active individuals can be a challenge in systems in which only the training of instructors, but not the recruitment of participants, has support from national public institutions, as the limited evaluation results available from the national seniors' sports programme are indicating. ${ }^{28}$

In summary, even in a country with well-established sports structures, ${ }^{11}$ Allez Hop has succeeded in reaching a previously underserved proportion of the population over more than a decade. Awareness has improved in the general population and the number of courses has increased accordingly. Methodological limitations do not allow direct inference about the effectiveness of the programme regarding changes in physical activity behaviour in participants. Although no causal links can be established, population-level data indicate changes in physical activity patterns in the main user group of Allez Hop and similar offers. Continuing implementation and an overall evaluation concept are desirable in large population-based programmes such as Allez Hop, ideally based on a national physical activity policy.

Acknowledgements The authors would like to thank Beat Ackermann, the former manager of Allez Hop, Gina Kienle, who has been involved with the Allez Hop course statistics, Isabelle Egger and Harald Reuter, who were in charge of the 2005 course

\section{What is already known on this topic}

Physical activity is an important public health issue. There is some evidence on the effectiveness of interventions for the promotion of walking; however, there is only limited evidence for the effectiveness of sports programmes in promoting physical activity at the population level, and only a few national multi-year physical activity promotion programmes have been systematically analysed.

\section{What this study adds}

- A large population-based physical activity promotion programme in Switzerland succeeded in reaching a previously underserved proportion of the population over more than a decade.

- Population-level data strongly indicate changes in physical activity behaviour in the main user group of the programme, in middle-aged women. 
evaluations, and Markus Lamprecht for his contribution to the analyses of the physical activity data from the Swiss Health Survey and the sports surveys.

Funding This study was funded by the Swiss Federation, Swiss Olympics, Federal Office of Sport, Swiss Council for Accident Prevention.

\section{Competing interests None.}

Contributors MW was involved in data analysis (course statistics, pretest posttest survey) and in writing the paper. EM-D was involved in the study design (pretest posttest survey) and in writing the paper. GFB was involved in the study design and data collection (pretest posttest survey) and in commenting on and revising the paper. HS was involved in the study design and data collection (sports surveys), data analysis (Swiss Health Surveys and sports surveys) and in commenting on and revising the paper. BWM was involved in the study design (pretest posttest survey, Swiss Health Surveys and sports surveys) and in writing the paper. All authors have had access to all data and have read and approved the final version of the paper. BWM is guarantor for the study.

\section{REFERENCES}

1. Cavill N, Kahlmeier S, Racioppi F. Physical activity and health in Europe. Evidence for action. Copenhagen: WHO Regional Office for Europe, 2006.

2. Daugbjerg SB, Kahlmeier S, Racioppi F, et al. Promotion of physical activity in the European region: content analysis of 27 national policy documents. J Phys Act Health 2009;6:805-17.

3. Physical Activity Guidelines Advisory Committee. Physical Activity Guidelines Advisory Committee Report 2008. Washington, DC: US Department of Health and Human Services, 2008:A-9.

4. Dawson J, Boller I, Foster C, et al. Evaluation of changes to physical activity amongst people who attend the Walking the Way to Health Initiative (WHI) Prospective Survey. Cheltenham: The Countryside Agency, 2006.

5. Steele K. Paths to health: 5th Annual Progress Report (1 September 2005 to 31 August 2006). 2006

6. Ogilvie D, Foster CE, Rothnie H, et al.; Scottish Physical Activity Research Collaboration. Interventions to promote walking: systematic review. BMJ 2007;334:1204.

7. Rootman I, Edwards P. The best laid schemes of mice and men. ParticipACTION's legacy and the future of physical activity promotion in Canada. Can J Public Health 2004;95(Suppl 2):S37-42.

8 Foster C. Guidelines for health-enhancing physical activity promotion programmes. The European Network for the Promotion of Health-Enhancing Physical Activity. Tampere: UKK Institute, 2000

9. Cavill N, Foster C, Oja P, et al. An evidence-based approach to physical activity promotion and policy development in Europe: contrasting case studies. Promot Educ 2006;13:104-11.

10. Vuori I, Lankenau B, Pratt M. Physical activity policy and program development: the experience in Finland. Public Health Rep 2004;119:331-45.

11. Lamprecht M, Fischer A, Stamm HP. Sport Schweiz 2008: das Sportverhalten der Schweizer Bevölkerung (Sport in Switzerland 2008: sport behaviour in the Swiss population). Magglingen: Swiss Federal Office of Sport, 2008

12. Lamprecht M, Stamm HP. Bewegung, Sport, Gesundheit. Fakten und Trends aus den Schweizerischen Gesundheitsbefragungen 1992, 1997 und 2002 (Physical activity, sport, health. Facts and trends from the Swiss Health Surveys 1992 1997, and 2002). In: Statsanté. Resultate zu den Gesundheitsstatistiken in der Schweiz. Neuchâtel: Swiss Federal Statistical Office, 2006.
13. Stamm H, Lamprecht M, Somaini B, et al. "Getting Switzerland to move": evaluation of a new "Sport for All" programme. Soz Präventivmed 2001:46:20-8

14. Wanner M, Martin-Diener E, Stamm HP, et al. 10 Jahre Allez Hop - Rückblick auf die selektiven Evaluationsansätze (Ten years of Allez Hop - retrospection and selective evaluation approaches). In: Knoll M, Woll A, eds. Schriften der Deutschen Vereinigung für Sportwissenschaft Band 174: Sport und Gesundheit in der Lebensspanne: 2008; Jahrestagung der dvs-Kommission Gesundheit, Bad Schönborn. Hamburg: Czwalina Verlag, 2008:90-6.

15. Dössegger A, Nützi C, Kienle G, et al. Experiences in nationwide recruiting for the "Allez Hop" physical activity programme. Schweiz Z Sportmed Sporttraumatol 2009;57:61-4.

16. Wanner M, Martin-Diener E, Popp C, et al. A semiautomated web-based approach for routine evaluation of physical activity courses. Schweiz Z Sportmed Sporttraumatol 2009;57:93-5.

17. Swiss Federal Statistical Office. Die Schweizerische Gesundheitsbefragung 2007 in Kürze. Konzept, Methode, Durchführung (The Swiss Health Survey in brief: concept, methods, implementation). Neuchâtel: Swiss Federal Office of Statistics, 2008.

18. Lamprecht M, Stamm HP. Sport Schweiz 2000: Sportaktivitäten und Sportkonsum der Schweizer Bevölkerung (Sport in Switzerland 2000: sport activities and sport consumption of the Swiss population). Basel, Bern, Zürich: Swiss Olympic, Sport Toto Association, 2000.

19. Stamm H, Fischer A, Lamprecht M. Evaluation des Bewegungsförderungsprogramms "Allez Hop". Resultate einer Internetbefragung von ausgebildeten Allez Hop Leiterlinnen (Evaluation of the physical activity promotion programme "Allez Hop". Results of an internet-based survey of trained Allez Hop instructors). Zürich: L\&S Sozialforschung und Beratung AG, 2007.

20. Nützi C. Evaluation der Werbekampagne Allez Hop (Evaluation of the advertisement campaign Allez Hop). Dübendorf: IPSO Sozial-, Marketing- und Personalforschung, 1998.

21. Egger I, Reuter H. Evaluation des Programms Allez Hop: Zwischenbericht (Evaluation of the programme Allez Hop: Interim report). Zurich: Institute of Social and Preventive Medicine, University of Zurich, 2005.

22. Egger I, Reuter H, Bauer G. Evaluation des Programms Allez Hop (2004-2006): Schlussbericht Juli 2006 (Evaluation of the programme Allez Hop (2004-2006). final report 2006). Zurich: Institute of Social and Preventive Medicine, University of Zurich, 2006

23. Victora CG, Habicht JP, Bryce J. Evidence-based public health: moving beyond randomized trials. Am J Public Health 2004;94:400-5.

24. Barreto ML. Efficacy, effectiveness, and the evaluation of public health interventions. J Epidemiol Community Health 2005:59:345-6.

25. Swiss Federal Office of Sport (FOSPO). Konzept des Bundesrates für eine Sportpolitik in der Schweiz (The Swiss Federal Government's concept for a national sport policy). Magglingen, Switzerland, 2000.

26. Swiss Federal Office of Sport (FOSPO). Konzept des Bundesrates für eine Sportpolitik in der Schweiz: Bericht zu den Umsetzungsmassnahmen 2003 bis 2006 (The Swiss Federal Government's concept for a national sport policy: report of the implementation measures 2003 to 2006). Magglingen, Switzerland, 2006.

27. Hillsdon M, Cavill N, Nanchahal K, et al. National level promotion of physical activity: results from England's ACTIVE for LIFE campaign. J Epidemiol Community Health 2001;55:755-61.

28. Wanner M, Wyss T, Schneider A, et al. Evaluation der Seniorensportangebote in der Schweiz: Bericht zur Pilotphase (Evaluation of senior sport offers in Switzerland: report of the pilot phase). Magglingen: Federal Office of Sport, 2005. 